\title{
Ric-8B, an Olfactory Putative GTP Exchange Factor, Amplifies Signal Transduction through the Olfactory- Specific G-Protein G $\alpha$ olf
}

\author{
Luiz Eduardo C. Von Dannecker, ${ }^{\star}$ Adriana F. Mercadante, ${ }^{\star}$ and Bettina Malnic \\ Departamento de Bioquímica, Instituto de Química, Universidade de São Paulo, São Paulo, Brazil
}

The olfactory system is able to detect a large number of chemical structures with a remarkable sensitivity and specificity. Odorants are first detected by odorant receptors present in the cilia of olfactory neurons. The activated receptors couple to an olfactory-specific G-protein (Golf), which activates adenylyl cyclase III to produce cAMP. Increased cAMP levels activate cyclic nucleotide-gated channels, causing cell membrane depolarization. Here we used yeast two-hybrid to search for potential regulators for G $\alpha$ olf. We found that Ric-8B (for resistant to inhibitors of cholinesterase), a putative GTP exchange factor, is able to interact with G $\alpha$ olf. Like G $\alpha$ olf, Ric-8B is predominantly expressed in the mature olfactory sensory neurons and also in a few regions in the brain. The highly restricted and colocalized expression patterns of Ric-8B and G $\alpha$ olf strongly indicate that Ric-8B is a functional partner for G $\alpha$ olf. Finally, we show that Ric-8B is able to potentiate G $\alpha$ olf-dependent cAMP accumulation in human embryonic kidney 293 cells and therefore may be an important component for odorant signal transduction.

Key words: olfactory neurons; signal transduction; GEF; G-protein; G-protein-coupled receptors; odorant receptors; synembryn

\section{Introduction}

Odorant signal transduction initiates when odorants bind and activate a large number of odorant receptors located in the cilia of the olfactory neurons in the nose (Buck and Axel, 1991; Buck, 2000). The activated receptors then couple to the olfactoryspecific G-protein G $\alpha$ olf to stimulate adenylyl cyclase type III. The concentration of cAMP in the cilia rises triggering the opening of cyclic nucleotide-gated channels, membrane depolarization, and generation of action potentials in the olfactory axon (Firestein, 2001; Ronnett and Moon, 2002; Mombaerts, 2004).

The odorant-induced production of cAMP is typically rapid and transient (Boekhoff et al., 1990; Breer et al., 1990). The ability of olfactory sensory neurons to adapt to odors allows the olfactory system to detect over a broader range of stimuli and also to rapidly recover the ability to sense an odorant. A large number of possible molecular mechanisms for signal termination have been described, such as odorant receptor phosphorylation (Boekhoff and Breer, 1992; Peppel et al., 1997), inhibition of adenylyl cyclase (Wei et al., 1998; Sinnarajah et al., 2001), stimulation of cAMP hydrolysis via activation of phosphodiesterases (Borisy et

Received Nov. 9, 2004; revised Feb. 5, 2005; accepted March 7, 2005.

This work was supported by grants from Fundação de Amparo à Pesquisa do Estado de São Paulo and Conselho Nacional de Desenvolvimento Cientifico e Tecnológico. We thank Linda Buck, Steve Lieberles, and James Contos for critically reading this manuscript. We are also grateful to Ronaldo B. Quaggio for help with the acquisition of microscope images. We also thank Glaucia M. Souza and Rachel Bagatini for assistance during the Northern blot experiments.

${ }^{*}$ L.E.C.V.D. and A.F.M. contributed equally to this work.

Correspondence should be addressed to Bettina Malnic, Departamento de Bioquímica, Instituto de Química, Universidade de São Paulo, C.P. 26077, CEP 05513-970, São Paulo, Brazil. E-mail: bmalnic@iq.usp.br. DOI:10.1523/JNEUROSCI.4595-04.2005

Copyright $\odot 2005$ Society for Neuroscience $\quad$ 0270-6474/05/253793-08\$15.00/0 al., 1992), and cAMP-gated channel regulation (Chen and Yau, 1994; Kurahashi and Menini, 1997; Zufall and Leinders-Zufall, 2000; Munger et al., 2001). The regulatory mechanisms described so far involve all components of the signaling cascade, except G $\alpha$ olf. Therefore, it is not clear yet whether G $\alpha$ olf can also be a target for regulatory events in the olfactory sensory neurons.

It is generally believed that the activation of heterotrimeric G-proteins is exclusively accomplished by the action of G-protein-coupled receptor (GPCRs), with only a few receptorindependent activators of G-protein signaling described (Strittmatter et al., 1990; Sato et al., 1996; Luo and Denker, 1999; Cismowski et al., 2000). Recently, two new mammalian heterotrimeric G $\alpha$ GTP exchange factors (GEFs) [Ric-8A and Ric-8B (for resistant to inhibitors of cholinesterase)] were identified (Tall et al., 2003). GEFs catalyze the exchange of GDP for GTP to generate an activated form of $G \alpha$, which is then able to activate a variety of effectors (Sprang, 2001). Biochemical characterization indicated that Ric-8A functions as a GEF for $\mathrm{G} \alpha_{\mathrm{q}}$, $\mathrm{G} \alpha_{\mathrm{i} 1}$, and $\mathrm{G} \alpha_{\mathrm{o}}$ but not for $\mathrm{G} \alpha_{\mathrm{s}}$ (Tall et al., 2003). Ric-8B, conversely, was shown to interact with $\mathrm{G} \alpha_{\mathrm{s}}$ and $\mathrm{G} \alpha_{\mathrm{q}}$ (Tall et al., 2003).

To search for potential regulators for the olfactory G-protein, we used yeast two-hybrid to screen an olfactory epithelium (OE) cDNA library using G $\alpha$ olf as bait and found Ric- $8 \mathrm{~B}$. We performed Northern blot analysis and show that Ric- $8 \mathrm{~B}$ is specifically expressed in the olfactory epithelium. In situ hybridization experiments indicated that Ric- $8 \mathrm{~B}$ is expressed in mature olfactory sensory neurons and that the expression colocalizes with that of G $\alpha$ olf in the olfactory epithelium. Ric- $8 \mathrm{~B}$ is also expressed in the regions of the brain previously shown to contain G $\alpha$ olf, such as the striatum, nucleus accumbens, and olfactory tubercle. In 
addition, our results show that Ric- $8 \mathrm{~B}$ is able to potentiate the ability of G $\alpha$ olf to activate cAMP production in heterologous cells, indicating that this putative GEF can regulate the function of G $\alpha$ olf.

\section{Materials and Methods}

Yeast two-hybrid screen. Yeast two-hybrid screening was performed using the DupLEX-A system (OriGene Technologies, Rockville, MD). The complete coding region of $\mathrm{G} \alpha$ olf was obtained by reverse transcription (RT)-PCR and subcloned into the EcoRI/XhoI sites of the yeast bait expression vector $\mathrm{pGilda}$ (Clontech, Palo Alto, CA) in fusion with the LexA DNA binding domain. The construct was transformed together with the lacZ reporter pSH18-34 into yeast strain RFY206 by the lithium acetate method (Golemis et al., 1999). An oligo-dT-primed cDNA library was prepared from mouse (C57BL/6J) OE poly $\left(\mathrm{A}^{+}\right) \mathrm{RNA}$ using the cDNA synthesis kit (Stratagene, La Jolla, CA). The cDNA was directionally cloned into the EcoRI/XhoI sites of the pJG4-5 target vector, in fusion with the B42 activator domain. The ligated products were electroporated into Escherichia coli $\mathrm{DH} 5 \alpha$ and resultant transformants $\left(5 \times 10^{6}\right.$ with an average insert size of $0.7 \mathrm{~kb}$ ) were plated onto Luria-Bertani medium/ ampicillin at a density of $5 \times 10^{5}$ colonies per plate $(150 \mathrm{~mm})$. The plasmid library was then purified using a Qiagen (Hilden, Germany) column after scraping the cells from the plate and was transformed into the yeast strain EGY48 using the lithium acetate method. Yeast transformations were done with an efficiency of $10^{4}$ colony forming units/ $\mu \mathrm{g}$ DNA. The RFY206 strain containing the bait and the reporter $\left(2 \times 10^{7}\right.$ cells) was mated with the strain EGY48 containing the library $\left(10^{7}\right.$ cells) as described by Golemis et al. (1999). Diploids were induced with galactose for the expression of both the bait and the library-encoded proteins, and interactors were selected on quadruple-deficient plates (Leu ${ }^{-}$, $\mathrm{Trp}^{-}$, His ${ }^{-}, \mathrm{Ura}^{-}$). Positive colonies were then assayed for $\beta$-galactosidase activity. The clones that grew on quadruple-deficient plates and turned blue in the $\beta$-galactosidase assay in the presence of galactose but not of glucose were selected. The cDNA inserts in the selected clones were analyzed through yeast-colony PCR using specific primers matching the pJG4-5 vector, and the DNA sequences were determined by automated sequencing. Clones of interest had their plasmids isolated and transformed into E. coli DH $5 \alpha$. The E. coli clones containing the pJG4-5 library constructs were rescued, and their plasmids were isolated. The plasmids were cotransformed with the lacZ reporter pSH18-34 into EGY48 and mated with the strain containing the bait to confirm the interactions.

Yeast interaction mating tests. Interactions between different baits and targets were checked using the method described by Finley and Brent (1994). Baits strains that harbor the lacZ reporter pSH18-34 and express different regions of $\mathrm{G} \alpha$ olf were prepared as described above. Briefly, bait strains were streaked in horizontal rows on a Glu His ${ }^{-} \mathrm{Ura}^{-}$plate and target strains in vertical columns on a Glu Trp ${ }^{-}$plate. The two plates were then replica plated onto a yeast/peptone/dextrose (YPD) plate, in which strains mated and formed diploids at the intersections of the streaks. The YPD plate was replica plated onto two indicator plates containing the following: (1) Gal His ${ }^{-} \mathrm{Ura}^{-} \mathrm{Trp}^{-}$5-bromo-4-chloro-3indolyl- $\beta$-D-galactopyranoside (X-gal) (shown in Fig. $1 c$ ); and (2) Gal $\mathrm{Leu}^{-} \mathrm{His}^{-} \mathrm{Ura}^{-} \mathrm{Trp}^{-}$(data not shown). Replicas were also plated onto control plates containing glucose instead of galactose, but no interactions were observed (data not shown).

Northern blot. Total RNA was prepared from tissues from C57BL/6J mice using TRIzol reagent (Invitrogen, Carlsbad, CA) according to the instructions of the manufacturer. The total RNA samples $(10 \mu \mathrm{g})$ were size fractionated on formaldehyde gels and blotted onto a Hybond $\mathrm{N}^{+}$ nylon membrane (Amersham Biosciences, Piscataway, NJ). The membrane was hybridized overnight at $37^{\circ} \mathrm{C}$ in hybridization buffer $[6 \times$ saline-sodium phosphate EDTA (SSPE), $5 \times$ Denhardt's solution, 0.1 $\mathrm{mg} / \mathrm{ml}$ sheared herring sperm DNA, 0.5\% SDS, and 50\% formamide] with a ${ }^{32} \mathrm{P}$-labeled probe prepared from Ric- $8 \mathrm{~B}$ (from the region corresponding to the entire coding region; GenBank accession number AY940666) by random priming (Invitrogen). The membrane was washed twice in $0.1 \%$ SDS and $0.5 \times$ SSPE at $65^{\circ} \mathrm{C}$ for $30 \mathrm{~min}$ and analyzed using a Storm 840 PhosphorImager (Amersham Biosciences).
RT-PCR. RNA was prepared from different mouse tissues using TRIzol reagent (Invitrogen). First, $1 \mu \mathrm{g}$ of total RNA plus $100 \mathrm{ng}$ of oligo-dT in $13.5 \mu$ l of DEPC-treated water were incubated for $2 \mathrm{~min}$ at $70^{\circ} \mathrm{C}$. The reaction was rapidly chilled on ice and used to synthesize cDNA in $20 \mu \mathrm{l}$ of $1 \times$ Superscript II first-strand buffer containing $0.5 \mathrm{~mm}$ deoxy NTP (dNTP), $3 \mathrm{~mm} \mathrm{MgCl}_{2}, 20 \mathrm{U}$ of RNase inhibitor (RNaseOUT; Invitrogen), and $200 \mathrm{U}$ of Superscript II reverse transcriptase at $42^{\circ} \mathrm{C}$ for $60 \mathrm{~min}$. The product was diluted to $100 \mu \mathrm{l}$ with DEPC-treated water. PCRs $(25 \mu \mathrm{l})$ containing $5 \mu \mathrm{l}$ of cDNA, $0.2 \mathrm{~mm} \mathrm{dNTP,} 1.5 \mathrm{~mm} \mathrm{MgCl}_{2}$, $0.5 \mu \mathrm{M}$ each of forward and reverse primers, and $1.25 \mathrm{U}$ of Platinum TaqDNA polymerase (Invitrogen) were heated to $95^{\circ} \mathrm{C}$ for $2 \mathrm{~min}$, followed by 25 (Ric- $8 \mathrm{~B}$ ) or 30 [G $\alpha$ olf and glyceraldehyde-3-phosphate dehydrogenase $(\mathrm{GAPDH})]$ thermal cycles of $95^{\circ} \mathrm{C}$ for $45 \mathrm{~s}, 58^{\circ} \mathrm{C}$ (Ric-8B), $57^{\circ} \mathrm{C}(\mathrm{G} \alpha$ olf $)$, or $55^{\circ} \mathrm{C}(\mathrm{GAPDH})$ for $45 \mathrm{~s}$, and $72^{\circ} \mathrm{C}$ for $1 \mathrm{~min}$, with a final incubation at $72^{\circ} \mathrm{C}$ for $10 \mathrm{~min}$. PCR products were analyzed in $1.5 \%$ agarose gels stained with ethidium bromide.

The primers AAGCTGGTTCGTCTCATGAC (forward) and GTCTGTGTCCGAGCTGGTC (reverse) were used to amplify the region across the ninth exon-containing isoform of Ric-8B, and the primers ATGGGGTGTTTGGGCAACAG (forward) and TCACAAGAGTTCGTACTGCTTG (reverse) were used to amplify G $\alpha$ olf.

In situ hybridization. In situ hybridization was performed according to Schaeren-Wiemers and Gerfin-Moser (1993). Noses or brains were dissected, respectively, from 2- and 6-week-old mice and freshly embedded in Tissue-Tek OCT compound (Sakura Finetek, Torrance, CA). Sequential $20 \mu \mathrm{m}$ sections were prepared with a cryostat and hybridized with digoxigenin-labeled cRNA probes prepared from Ric-8B (region corresponding to nucleotides 790-2256), G $\alpha$ s, and G $\alpha$ olf (corresponding to the full coding regions) cDNAs. Color reactions were performed for $1.5 \mathrm{~h}$ in the olfactory epithelium and overnight in the brain, except for the G $\alpha$ s reaction on the coronal brain section, which was performed for $1.5 \mathrm{~h}$.

Tissue culture cAMP detection. The cDNAs corresponding to the fulllength sequence of Ric-8B, Ric- $8 \mathrm{~B} \Delta 9$ (GenBank accession number AY940667), G $\alpha$ olf, and dopamine $D_{1}$ receptor $\left(D_{1} R\right)$ were cloned by PCR using CDNAs prepared from mouse olfactory epithelium and subcloned into the pcDNA3.1 expression vector containing a FLAG epitope. Expression vectors for $\mathrm{G} \alpha \mathrm{s}$ and the $\beta_{2}$-adrenergic receptor $\left(\beta_{2} \mathrm{AR}\right)$ were kindly provided by Stephen Liberles and Linda Buck (Fred Hutchinson Cancer Research Center, Seattle, WA). G $\alpha$ olf and Ric-8B protein expression was checked by Western blot using, respectively, an anti-G $\alpha$ olf antibody (Santa Cruz Biotechnology, Santa Cruz, CA) and an anti-FLAG antibody (Sigma, St. Louis, MO) (data not shown).

Human embryonic kidney 293 (HEK293) cells were maintained in DMEM supplemented with $10 \%(\mathrm{v} / \mathrm{v})$ fetal calf serum, $1 \mathrm{~mm}$ glutamine, $50 \mu \mathrm{g} / \mathrm{ml}$ streptomycin, and $50 \mathrm{U} / \mathrm{ml}$ penicillin at $37^{\circ} \mathrm{C}$ with $5 \% \mathrm{CO}_{2}$. Cells $\left(0.5 \times 10^{5}\right)$ were plated into each well of a 96-well plate for 16-20 $\mathrm{h}$ and transfected using lipofectamine reagent (Invitrogen) with constructs expressing the different cDNAs (100 ng/well). After $3 \mathrm{~h}$ of transfection, medium was replaced by serum-free media containing the agonist $(10 \mu \mathrm{M})$, and cells were incubated for another $40 \mathrm{~h}$. Shorter periods of agonist stimulation (10, 30, or $120 \mathrm{~min}$ ) produced similar results (see Fig. $5 c$ ). cAMP was measured using the cAMP Enzymeimmunoassay (Amersham Biosciences) following the protocol of the manufacturer.

\section{Results}

\section{Goolf interacts with Ric-8B}

An olfactory epithelium cDNA library was screened with G $\alpha$ olf as bait (see Materials and Methods). We obtained 74 clones. Of these, 64 showed strong interactions (strong blue color developed after $12 \mathrm{~h}$ of incubation in the presence of X-gal), and the other 10 showed comparatively much weaker interactions with the bait (detected after $24 \mathrm{~h}$ in the presence of X-gal). The 64 clones showing strong interaction with G $\alpha$ olf encode the full-length sequence of Ric-8B. Ric-8B cDNA is 1683 bp long and encodes a protein of 560 amino acids (Fig. 1a). The deduced amino acid sequence does not show conserved motifs or any other valuable information on the protein, except that Ric- $8 \mathrm{~B}$ shares $\sim 40 \%$ amino acid sequence identity with Ric-8A, which was shown to 


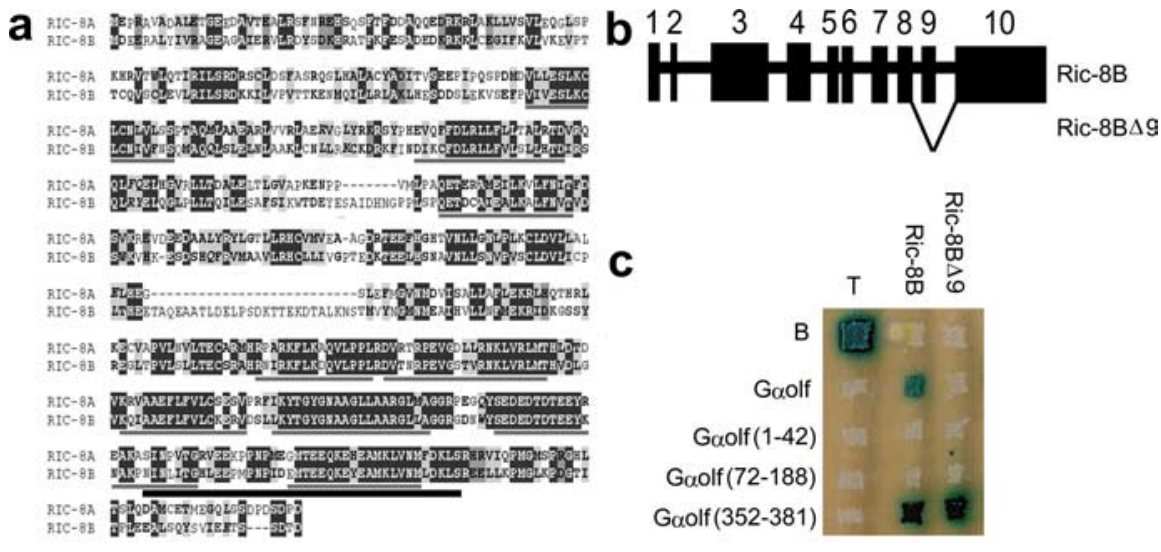

Figure 1. Ric-8B interacts with G $\alpha$ olf. $\boldsymbol{a}$, Amino acid sequence alignment of mouse Ric-8B and Ric-8A. Shaded sequences indicate areas of amino acid identity. The nine synembryn signatures are underlined in gray. The region corresponding to exon 9 is underlined in black. $\boldsymbol{b}$, Schematic representation of the Ric-8B gene structure. Exons are represented by black boxes, and introns are represented by thick lines. The initiator methionine ATG codon is in exon 1, and the stop codon is in the beginning of exon 10. The Ric- $8 \mathrm{~B}$ cDNA contains all of the 10 exons. The alternative spliced variant (denominated Ric-8B $\Delta 9$ ) also identified in the two-hybrid screen does not contain exon 9, as indicated. c, Interaction between Ric-8B and G $\alpha$ olf. Bait strains expressing fulllength $\mathrm{G} \alpha$ olf (amino acids 1-381) or different regions of $G \alpha$ olf (amino acids 1-42,72-188, or 352-381) were mated with target strains expressing full-length Ric-8B or Ric- $8 \mathrm{~B} \Delta 9$. X-gal was used to score positive interactions. pBait (B), which constitutively expresses a LexA bait fusion protein that interacts with the fusion protein from pTarget (T), was used as positive control.

work as a GEF for a subset of G $\alpha$ subunits (Tall et al., 2003). These two proteins share nine conserved synembryn signatures that show $58-90 \%$ amino acid sequence identity (Fig. 1a). However, whether Ric-8B acts as a GEF has yet to be determined.

The remaining clones (which showed weaker interactions with G $\alpha$ olf) contained an alternatively spliced variant of Ric- $8 \mathrm{~B}$ that lacks exon 9 (denominated here as Ric-8B $\Delta 9$ ) (Fig. $1 a, b$ ), indicating that this region of Ric- $8 \mathrm{~B}$ is important for the interaction between Ric-8B and G $\alpha$ olf.

We next asked which region of $\mathrm{G} \alpha$ olf is required for the interaction with Ric-8B. Baits containing different regions of G $\alpha$ olf were constructed and checked for their ability to interact with Ric-8B (Fig. 1c). A fragment containing only the last 30 amino acids of G $\alpha$ olf (G $\alpha$ olf 352-381) retained the ability to interact with Ric-8B, but baits containing N-terminal (G $\alpha$ olf $1-42$ ) or central regions (G $\alpha$ olf72-188) of G $\alpha$ olf showed no interaction, indicating that the $\mathrm{C}$-terminal region of $\mathrm{G} \alpha$ olf is involved in the interaction. It has been demonstrated previously that the C-terminal region of $\mathrm{G} \alpha$ subunits plays an important role in specifying receptor interaction (Conklin et al., 1993). Hence, if olfactory receptors (ORs) and Ric-8B can both interact with the $\mathrm{C}$-terminal region of $\mathrm{G} \alpha \mathrm{olf}$, it is possible that these interactions are mutually exclusive.

Consistent with what was observed during the screening, we could barely detect interaction between Ric-8B $\Delta 9$ and G $\alpha$ olf. Conversely, Ric- $8 \mathrm{~B} \Delta 9$ retains the ability to interact with the $\mathrm{C}$-terminal region of $\mathrm{G} \alpha$ olf (Fig. 1c). These results suggest the existence of a second domain in G $\alpha$ olf besides the $\mathrm{C}$ terminus that is involved in binding to Ric- $8 \mathrm{~B}$ and that the sequence corresponding to exon 9 of Ric- $8 \mathrm{~B}$ is required.

\section{Tissue distribution of Ric-8B expression}

We next performed Northern blot experiments to examine the tissue distribution of Ric-8B expression. Total RNA prepared from 10 different mouse tissues was size fractionated, blotted onto membranes, and hybridized with a ${ }^{32} \mathrm{P}$-labeled probe corresponding to the Ric-8B cDNA. Control hybridization was performed with a probe prepared from GAPDH. The Ric-8B probe hybridized to two major bands of $\sim 2$ and 3 $\mathrm{kb}$ only in the olfactory epithelium (Fig. 2a). A smaller and fainter band was also detected in the skeletal muscle, but, in general, no other tested tissue showed Ric-8B expression. We also used RT-PCR, which is a more sensitive method than Northern blot, to amplify Ric- $8 \mathrm{~B}$ and $\mathrm{G} \alpha$ olf from the same tissues analyzed in Figure $2 a$. Using this method, we were able to detect lower levels of Ric-8B expression also in the eye, brain, skeletal muscle, and heart (Fig. 2b). Goolf expression was restricted to the olfactory epithelium and the brain (Fig. 2b). These data show that Ric- $8 \mathrm{~B}$ gene is preferentially transcribed in the olfactory epithelium and, to a lower extent, in the brain, eye, and muscle.

Because we identified two different splicing variants of the Ric-8B mRNA during the screening (Fig. $1 a, b$ ), we conducted semiquantitative RT-PCR experiments with primers that amplify across the ninth exon to determine which isoform is predominant in the olfactory epithelium. Our results indicate that Ric- $8 \mathrm{~B}$ and Ric- $8 \mathrm{~B} \Delta 9$ isoforms are expressed in equivalent amounts (Fig. 2c).

\section{Expression of Ric-8B and Goolf is colocalized in the olfactory epithelium}

It was demonstrated previously that Ric- $8 \mathrm{~B}$ interacts with $\mathrm{G} \alpha$ s subunits (Tall et al., 2003). It is therefore not surprising that G $\alpha$ olf also interacts with Ric-8B, because G $\alpha$ olf shows $88 \%$ amino acid sequence identity to $\mathrm{G} \alpha_{\mathrm{s}}$ (Jones and Reed, 1989). This raises the question of which one of the two subunits, $\mathrm{G} \alpha$ s or $\mathrm{G} \alpha$ olf, is the real biological target for Ric-8B. To address this question, we compared the localization of Ric- $8 \mathrm{~B}, \mathrm{G} \alpha$, and $\mathrm{G} \alpha$ olf expression in the OE and in the brain.

In situ hybridization experiments were performed with digoxigenin-labeled antisense cRNA probes for Ric-8B, $\mathrm{G} \alpha$, and G $\alpha$ olf. High-stringency conditions were used to ensure that probes detected only very closely related transcripts. The olfactory sensory neurons in the olfactory epithelium express Ric-8B, G $\alpha$ olf, and $\mathrm{G} \alpha_{\mathrm{s}}$ (Fig. $3 a-c$ ), but the localization of the neurons expressing the different genes within the epithelium differs: whereas Ric- $8 \mathrm{~B}$ and G $\alpha$ olf are predominantly expressed in mature neurons located in the broad central area of the epithelium, $\mathrm{G} \alpha_{\mathrm{s}}$ is expressed throughout the epithelium, including the basal layer that contains precursors and immature neurons (Fig. $3 g-i$ ). No signal was detected when the corresponding sense probes were used (Fig. $3 d-f$ ). Figure $3 j-l$ shows hybridization of probes for Ric-8B ( $j), G \alpha$ olf $(k)$, and olfactory marker protein (OMP) (l) to coronal sections through an anterior part of the nose that contains both olfactory and vomeronasal epithelia neurons. OMP is expressed in both types of neurons. Like G $\alpha$ olf (Berghard et al., 1996), Ric-8B is not expressed in the vomeronasal neurons.

\section{Expression of Ric-8B and Goolf is colocalized in the brain}

As reported previously, $\mathrm{G} \alpha_{\mathrm{s}}$ is widely expressed in the brain, except in the striatum, nucleus accumbens, and olfactory tubercle (Belluscio et al., 1998; Zhuang et al., 2000) (Fig. 4). Although G $\alpha$ olf is preferentially expressed in the olfactory epithelium, it is also expressed in some regions of the brain, namely the striatum 
a
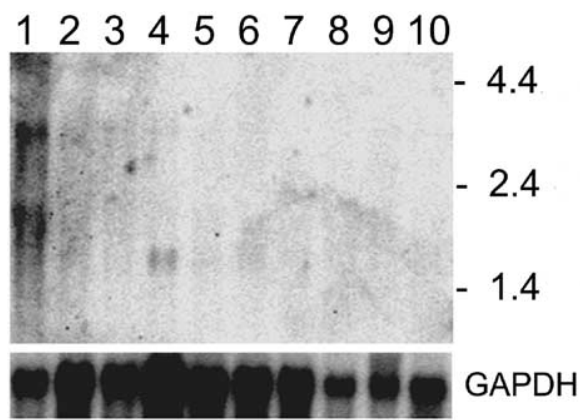

b

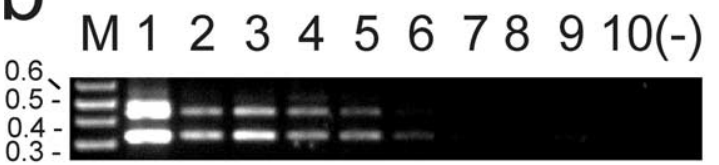

Ric-8B

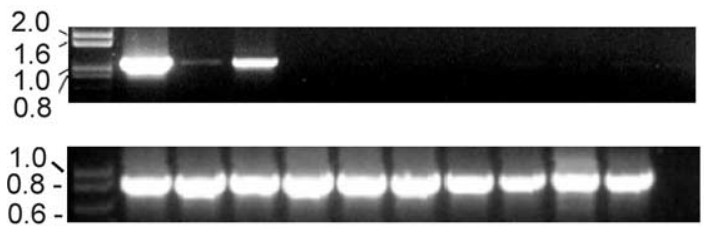

Gaolf GAPDH

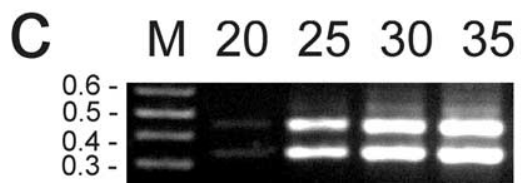

Figure 2. Ric-8B is mainly expressed in the olfactory epithelium. $\boldsymbol{a}$, Northern blot analysis of mouse total RNA: 1 , olfactory epithelium; 2 , whole eye; 3 , brain; 4 , skeletal muscle; 5 , heart; 6 , kidney; 7 , liver; 8 , lung; 9 , testis; 10 , thymus. A probe prepared from Ric-8B was hybridized using stringent conditions. Hybridization with GAPDH probe indicated that similar amounts of RNA were loaded in each lane. Sizes are given in kilobases. $\boldsymbol{b}$, RT-PCR was conducted to amplify Ric-8B, G $\alpha$ olf, and GAPDH from the same tissues as in $\boldsymbol{a}$. (-), Negative control (no CDNA was added to the reaction). c, Semiquantitative RT-PCR was conducted to amplify Ric-8B from olfactory epithelium RNA after 20, 25, 30, and 35 cycles, as indicated. The PCR product sizes expected for Ric-8B using the primers that flank the ninth exon are 462 bp (Ric-8B) and 342 bp (Ric-8B $\Delta 9)$. M, Molecular weights are given in kilobases.

(made up of the caudate nucleus and putamen), nucleus accumbens, olfactory tubercle, piriform cortex, dentate gyrus, CA3 region of the hippocampus, and Purkinje cells of the cerebellum (Belluscio et al., 1998; Zhuang et al., 2000) (Fig. 4c,h). This nonoverlapping pattern of $\mathrm{G} \alpha$ s and $\mathrm{G} \alpha$ olf expression in the brain suggests that $\mathrm{G} \alpha$ olf is the functional G-protein that stimulates cAMP production in the regions that lack $\mathrm{G} \alpha_{\mathrm{s}}$.

We performed in situ hybridization to determine the distribution of Ric-8B mRNA in the brain. Sagittal (Fig. $4 a-f$ ) and coronal (Fig. $4 g-i$ ) sections cut through the mouse brain were hybridized with digoxigenin-labeled antisense cRNA probes for Ric-8B (Fig. 4a,g), G $\alpha$ olf (Fig. $4 c, h$ ), and $\mathrm{G} \alpha_{\mathrm{s}}$ (Fig. 4e,i). Interestingly, Ric-8B mRNA was colocalized with that of G $\alpha$ olf, except for the Purkinje cells in the cerebellum, in which no Ric-8B mRNA was detected. As mentioned above, Ric- $8 \mathrm{~B}$ is able to interact with both $\mathrm{G} \alpha_{\mathrm{s}}$ and $\mathrm{G} \alpha$ olf subunits in the yeast two-hybrid system (Fig. 1c) (Tall et al., 2003). Nevertheless, the fact that Ric- $8 \mathrm{~B}$ is predominantly expressed in regions that show expression of Goolf and little or no expression of $\mathrm{G} \alpha$ s strongly indicates that G $\alpha$ olf must be its physiological interactor.

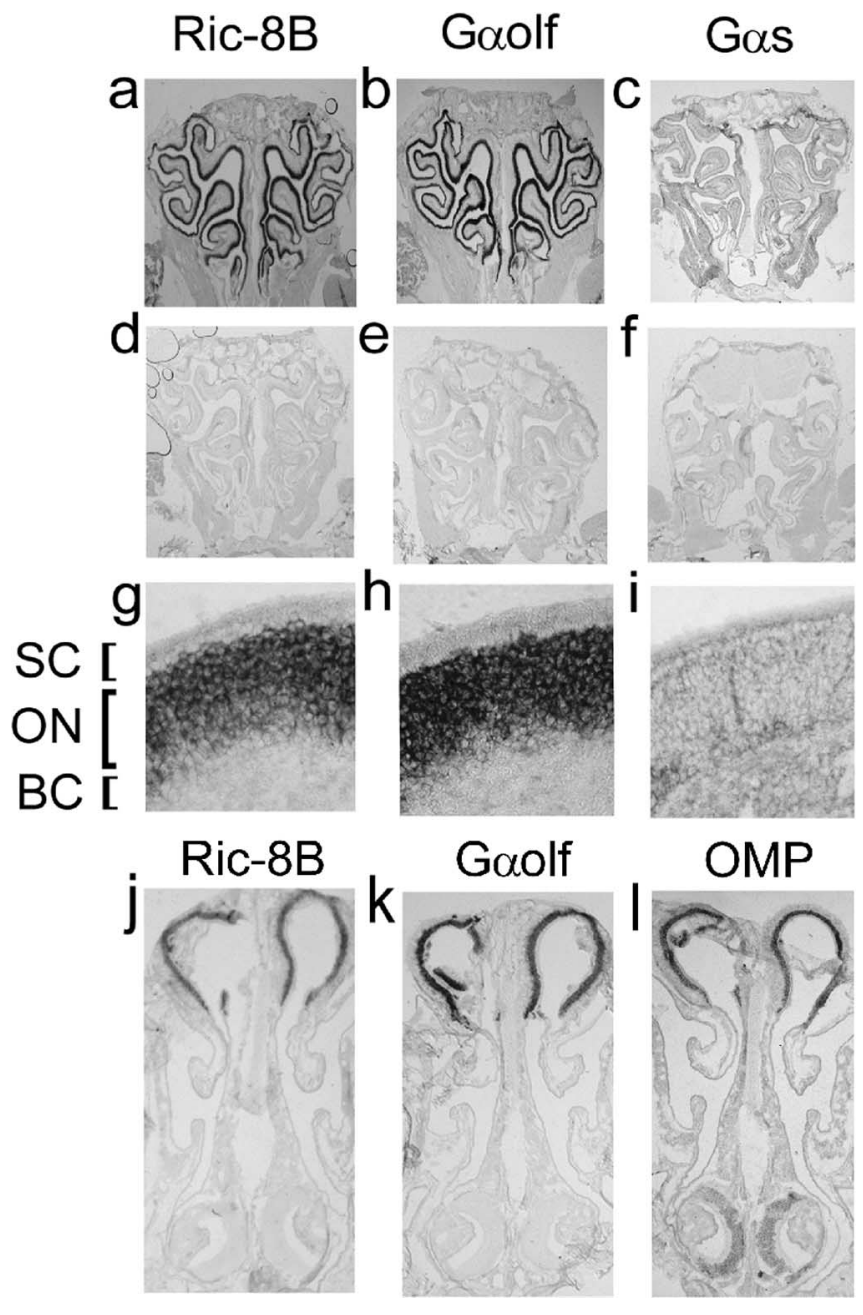

Figure 3. Distribution of Ric-8B mRNA in the olfactory system. $\boldsymbol{a}-\boldsymbol{f}$, Coronal sections through the nasal cavity were hybridized with antisense digoxigenin-labeled probes specific for Ric-8B $(\boldsymbol{a})$, $G \alpha 0$ lf $(\boldsymbol{b})$, and $G \alpha_{\mathrm{s}}(\boldsymbol{c})$. Corresponding sense digoxigenin-labeled probes were used as negative controls $(\boldsymbol{d}-\boldsymbol{f})$. Neurons in the olfactory epithelium that hybridize with the Ric-8B probe show a pattern typical of that seen with the $G \alpha$ olf probe. $\boldsymbol{g}-\boldsymbol{i}$, Magnified regions from $\boldsymbol{a}-\boldsymbol{c}$ showing the distribution of stained cells within the olfactory epithelium. Ric-8B $(\boldsymbol{g})$ and $\mathrm{G} \alpha$ olf $(\boldsymbol{h})$ probes hybridize to mature neurons (ON) but not to the most apical layer of cells closest to the lumen [supporting cells $(\mathrm{SC})$ ] or to the immature neurons localized in the basal layer of the epithelium (BC). The $G \alpha$ s probe (i), conversely, hybridizes preferentially to immature cells localized in the basal layer of the epithelium. $\boldsymbol{j}-\boldsymbol{I}$, Sections cut through the olfactory and vomeronasal epithelia. Ric- $8 \mathrm{~B}(\boldsymbol{j})$ and $\mathrm{G} \alpha \mathrm{olf}(\boldsymbol{k})$ probes hybridize to neurons in the olfactory epithelium but not to vomeronasal neurons. OMP $(\boldsymbol{I})$ is expressed in the olfactory and vomeronasal epithelia.

Ric-8B activates cAMP accumulation in the presence of Goolf Previous studies had shown that the $\beta_{2}$ AR can couple with G $\alpha$ olf (Jones and Reed, 1989; Liu et al., 2001). To verify whether Ric-8B is able to regulate the activity of G $\alpha$ olf, we transfected HEK293 cells with the expression vectors for $\mathrm{G} \alpha$ olf and the $\beta_{2} \mathrm{AR}$ in the presence or absence of Ric-8B. cAMP production in each case was measured and compared with the cAMP levels of untransfected cells. Both expression of $\beta_{2} \mathrm{AR}$ alone and coexpression of $\mathrm{G} \alpha \mathrm{olf}$ and $\beta_{2} \mathrm{AR}$ increased cAMP accumulation to similar levels (fivefold to sevenfold the control levels) in the presence of the agonist isoproterenol (Fig. 5a). These results indicate that the $\beta_{2} \mathrm{AR}$ is able to couple to endogenous pathways to induce cAMP accumulation in HEK293 cells and are consistent with previous observations that G $\alpha$ olf works poorly in heterologous systems when compared with $\mathrm{G} \alpha_{\mathrm{s}}$ (Jones and Reed, 1989; Jones et al., 1990). 

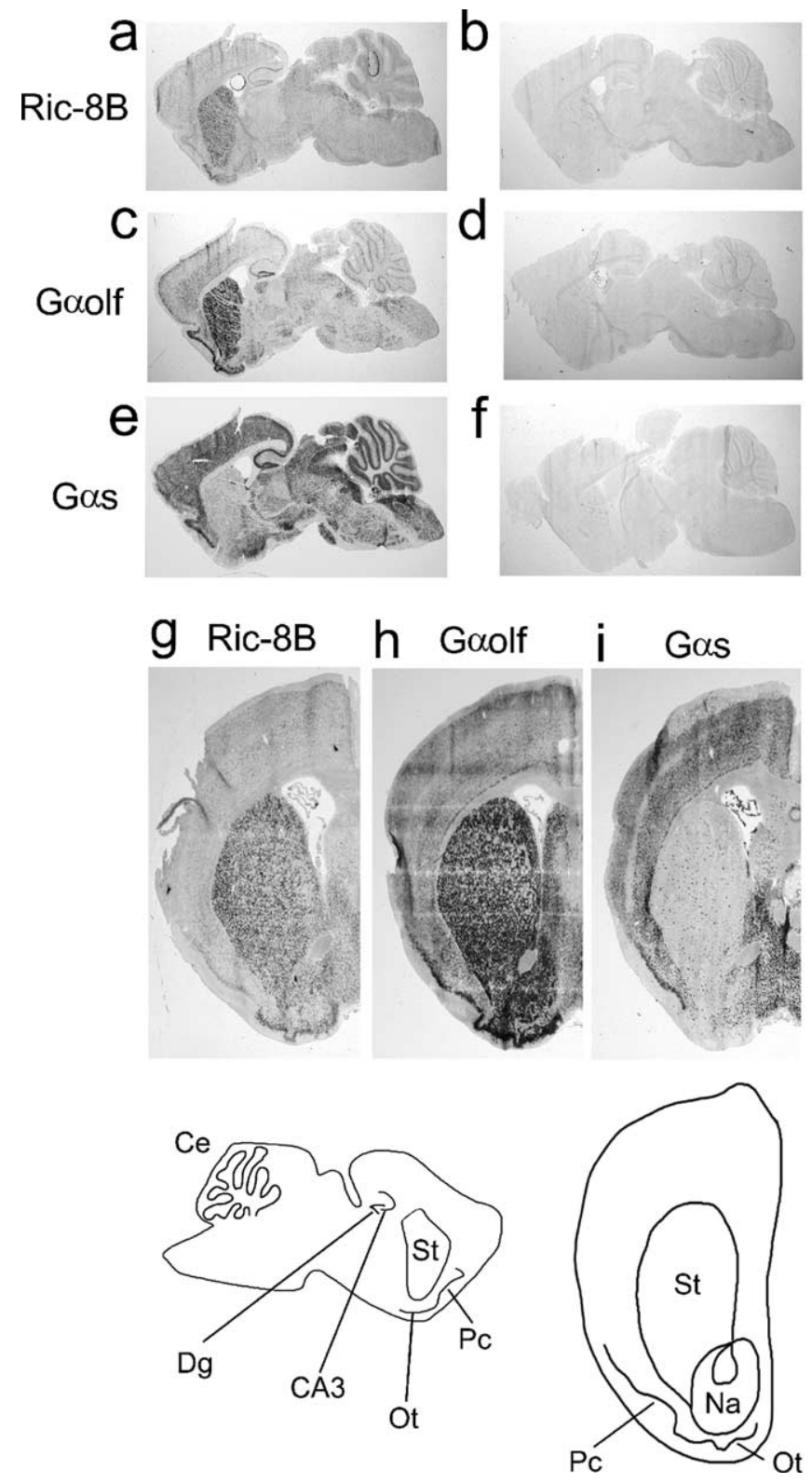

Figure 4. Comparison of mRNA expression patterns for Ric- $8 B$, $G \alpha$ olf, and $G \alpha$ in the adult mouse brain. $\boldsymbol{a}-\boldsymbol{f}$, Sagittal brain sections were hybridized with antisense digoxigenin-labeled probes specific for Ric-8B $(\boldsymbol{a}), \mathrm{G} \alpha$ olf $(\boldsymbol{c})$, and $G \alpha_{s}(\boldsymbol{e})$. Corresponding sense digoxigenin-labeled probes were used as negative controls $(\boldsymbol{b}, \boldsymbol{d}, \boldsymbol{f}) \cdot \boldsymbol{g}-\boldsymbol{i}$, Coronal brain sections were hybridized with antisense digoxigenin-labeled probes specific for Ric-8B $(\boldsymbol{g}), \mathrm{G} \alpha \mathrm{olf}(\boldsymbol{h})$, and $\mathrm{G} \alpha_{\mathrm{s}}(\boldsymbol{i})$. Ric-8B is expressed in regions known to express high levels of $G \alpha$ olf and that show little or no expression of $\mathrm{G} \alpha_{\mathrm{s}}$ : the striatum (St), nucleus accumbens $(\mathrm{Na})$, and olfactory tubercle (Ot). Ric- $8 \mathrm{~B}$ expression was also detected in the piriform cortex $(\mathrm{Pc})$, dentate gyrus $(\mathrm{Dg})$, and $\mathrm{CA} 3$ region of the hippocampus, in which both $\mathrm{G} \alpha$ olf and $\mathrm{G} \alpha$ s are also expressed. Ce, Cerebellum.

Surprisingly, the coexpression of G $\alpha$ olf, $\beta_{2} \mathrm{AR}$, and Ric- $8 \mathrm{~B}$ induced much higher levels of cAMP accumulation in the presence of isoproterenol ( $\sim 15$-fold the control levels) (Fig. $5 a)$. This amplification effect is dependent on receptor activation, because no effect was detected when G $\alpha$ olf was cotransfected with Ric-8B alone (Fig. 5a). It is also dependent on G $\alpha$ olf, because no effect was observed when Ric- $8 \mathrm{~B}$ was cotransfected with $\beta_{2} \mathrm{AR}$ alone (Fig. 5a).

Interestingly, Ric- $8 \mathrm{~B} \Delta 9$, the alternatively spliced version of Ric-8B lacking exon 9, showed no significant effect on the G $\alpha$ olfdependent cAMP generation: in the presence of isoproterenol,
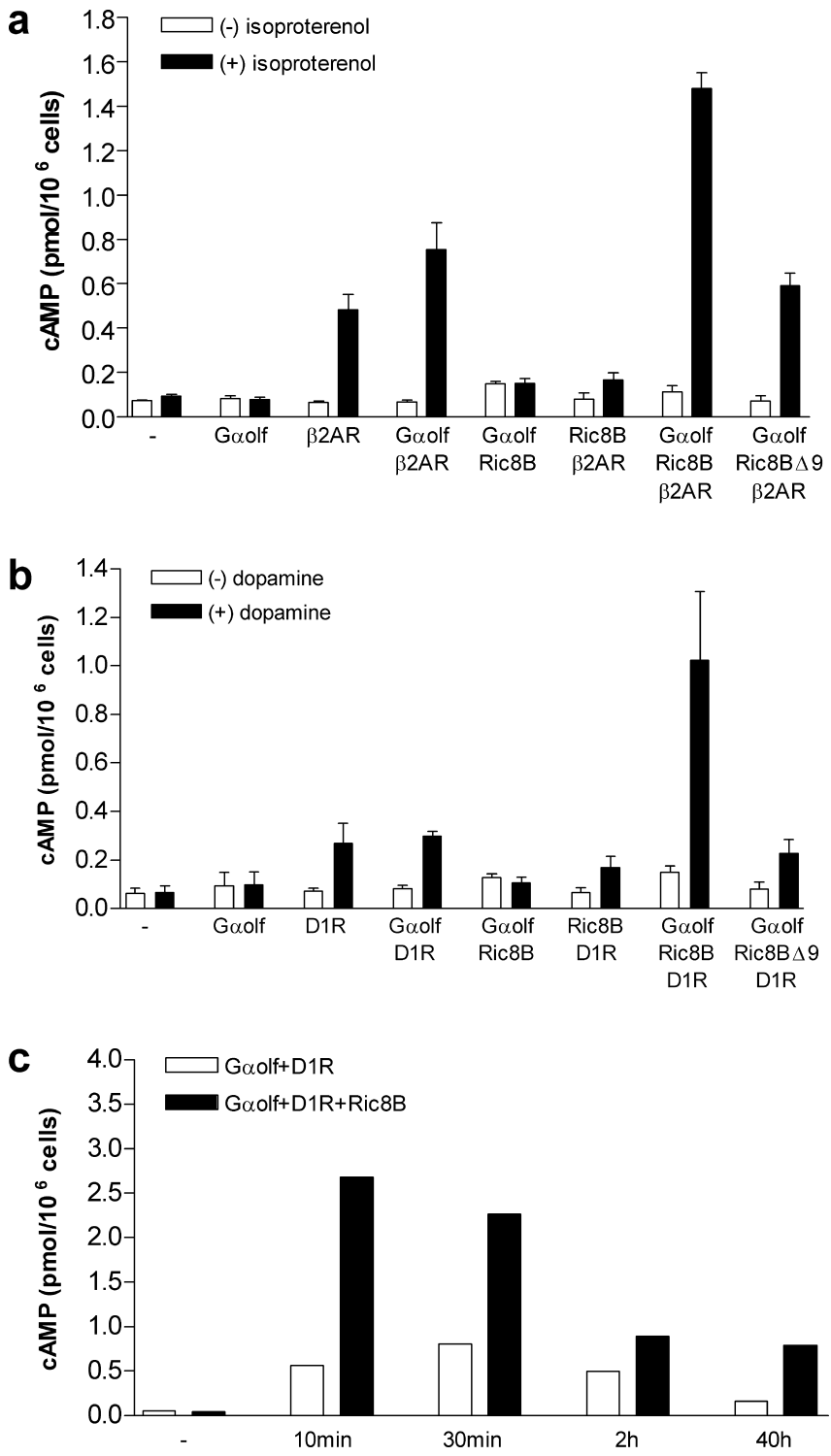

Figure 5. Amplification of CAMP accumulation by Ric-8B. $\boldsymbol{a}$, Production of CAMP was measured in HEK293 cells transfected as indicated with G $\alpha$ olf, Ric-8B, Ric-8B $\Delta 9, G \alpha_{s^{\prime}}$ and $\beta_{2} A R$ expression vectors. Activation was recorded in the absence (white bars) or presence (black bars) of $10 \mu \mathrm{m}$ isoproterenol. The data are expressed as the means \pm SE from three different experiments, each performed in duplicate. CAMP accumulation is presented as picomoles per million cells. - indicates untransfected cells (control). $\boldsymbol{b}$, Same as in $\boldsymbol{a}$, except that cells were transfected with $D_{1}$ R instead of $\beta_{2} A R$ and the agonist was dopamine $(10 \mu \mathrm{M})$. c, Cells were cotransfected with $G \alpha$ olf and $D_{1} R$ (white bars) or with $G \alpha$ olf, $D_{1} R$, and Ric- $8 B$ (black bars). Production of CAMP was measured after dopamine stimulation for the indicated periods of time. - indicates that no dopamine was added. The data are expressed as the means of two independent experiments.

the levels of cAMP accumulation in cells coexpressing G $\alpha$ olf, $\beta_{2} \mathrm{AR}$, and Ric- $8 \mathrm{~B} \Delta 9$ were similar to the ones in cells coexpressing only G $\alpha$ olf and $\beta_{2} \mathrm{AR}$ (Fig. $5 a$ ). The expression levels of Ric-8B and Ric- $8 \mathrm{~B} \Delta 9$ protein in HEK293 cells were checked through Western blotting and indicated that both isoforms are expressed in equivalent amounts (data not shown). In conjunction with the fact that Ric- $8 \mathrm{~B}$ interacts with $\mathrm{G} \alpha$ olf although Ric- $8 \mathrm{~B} \Delta 9$ does not (Fig. 1c), these results indicate that the signaling amplification effect caused by Ric- $8 \mathrm{~B}$ depends on a direct interaction between G $\alpha$ olf and Ric-8B.

It has been shown previously that coupling of $\mathrm{D}_{1}$ Rs to adenylyl cyclase in the striatum is mediated by G $\alpha$ olf (Hervé et al., 1993, 
2001; Zhuang et al., 2000). To verify whether Ric-8B is also able to regulate $D_{1} R$ signaling through G $\alpha$ olf, we performed experiments identical to the ones described above, except that we now used $D_{1} R$ instead of $\beta_{2} A R$ and dopamine instead of isoproterenol as the agonist. We observed that $\mathrm{D}_{1} \mathrm{R}$ is also able to couple to endogenous HEK293 pathways when expressed alone or in conjunction with G $\alpha$ olf (threefold the control levels) (Fig. 5b) but less efficiently than $\beta_{2} \mathrm{AR}$. As shown for $\beta_{2} \mathrm{AR}$, coexpression of $\mathrm{D}_{1} \mathrm{R}, \mathrm{G} \alpha \mathrm{olf}$, and Ric- $8 \mathrm{~B}$ resulted in amplification of cAMP accumulation in the presence of the agonist, whereas coexpression of $\mathrm{D}_{1} \mathrm{R}, \mathrm{G} \alpha$ olf, and Ric- $8 \mathrm{~B} \Delta 9$ did not (Fig. $5 b$ ). Because Ric- $8 \mathrm{~B}$ is expressed in the striatum, these results suggest that it might also be involved in the regulation of the dopamine signaling pathways in the brain.

We also performed the cAMP accumulation experiments with agonist stimulation for different periods of time, as indicated in Figure $5 c$. In these experiments, we compared the amounts of cAMP accumulation in cells coexpressing Goolf and $D_{1} R$ (white bars) with cells coexpressing G $\alpha$ olf, $\mathrm{D}_{1} \mathrm{R}$, and Ric-8B (black bars) after $10 \mathrm{~min}, 30 \mathrm{~min}, 2 \mathrm{~h}$, and $40 \mathrm{~h}$ of dopamine stimulation. The Ric-8B-induced amplification effect was observed at all tested times. Although the average amplification effect was approximately the same for each time (cAMP produced in the presence of Ric- $8 \mathrm{~B}$ is between 2.5- and 5-fold the cAMP produced in the absence of Ric-8B), the shorter the periods of agonist stimulation, the higher was the total amount of cAMP produced. These results indicate that Ric- $8 \mathrm{~B}$ can directly modulate signaling through the dopamine receptor, possibly through a direct effect on GTP exchange.

\section{Discussion}

The transduction of chemical signals by ORs represents the initial step in a cascade of events that ultimately leads to the discrimination and perception of odorants. ORs signal through the downstream components G $\alpha$ olf, type III adenylyl cyclase, and a cyclic nucleotide-gated ion channel, which are highly enriched in the cilia of olfactory neurons (Ronnett and Moon, 2002; Mombaerts, 2004). The observation that knock-out mice for these three proteins are anosmic (they lack the sense of smell) (Brunet et al., 1996; Belluscio et al., 1998; Wong et al., 2000; Zheng et al., 2000 ) is consistent with a fundamental role for these components in olfactory sensory transduction.

In an effort to identify possible regulators for odor signal transduction, we screened a mouse olfactory epithelium cDNA library with $\mathrm{G} \alpha$ olf as bait. The interacting clones encode Ric- $8 \mathrm{~B}$. Ric-8 was first isolated from a Caenorhabditis elegans screening for mutants resistant to inhibitors of cholinesterase (Ric) (Miller et al., 1996). These mutants were selected for their ability to survive the effects of inhibitors of acetylcholinesterase, which cause a toxic accumulation of secreted acetylcholine at synapses (Miller et al., 2000). The Ric mutant genes code for proteins that function in neurotransmitter secretion, causing a decrease in the amount of acetylcholine at the synapses, what compensates for the druginduced accumulation of the neurotransmitter.

In addition to its role in the adult nervous system, Ric- 8 is also required to regulate a subset of centrosome movements in the early embryo and therefore is also denominated synembryn (Miller and Rand, 2000). Ric-8B and Ric-8A are the mammalian homologs for the $C$. elegans Ric-8/synembryn. A recent study demonstrated that Ric-8A is a GEF for a subset of $\mathrm{G} \alpha$-proteins (Tall et al., 2003). The fact that Ric-8B is related to Ric-8A in amino acid sequence (both sequences show conserved synem- bryn motifs) (Fig. 1a) and also binds $\mathrm{G} \alpha$ subunits suggests that Ric-8B may also be a GEF.

Consistent with the possible role as a GEF, Ric- $8 \mathrm{~B}$ is able to potentiate Goolf-dependent cAMP accumulation in HEK293 cells. In this case, the $\beta_{2} \mathrm{AR}$ would activate G $\alpha$ olf, which would hydrolyze GTP. Ric- $8 \mathrm{~B}$ would bind to G $\alpha$ olf and catalyze the release of GDP and the subsequent uptake of GTP, reactivating it. However, whether Ric- $8 \mathrm{~B}$ is really a GEF and works as a GEF for G $\alpha$ olf still needs to be determined. It is also possible that Ric- $8 \mathrm{~B}$ is an effector for G $\alpha$ olf and serves as a GEF for downstream targets, as was shown for other GEF proteins. It has been demonstrated, for example, that $\mathrm{G} \alpha_{13}$ directly activates p115RhoGEF, which in turn promotes GDP dissociation from the small GTPase Rho, allowing it to be activated again by GTP (Hall, 1998).

To date, a very small number of GEFs for heterotrimeric G-proteins has been described. It has been demonstrated, for example, that GAP-43, an intracellular protein closely associated with neuronal growth, stimulates GTP- $\gamma$-S binding to $G_{o}$, which is a major component of the neuronal growth cone membrane (Strittmatter et al., 1990). Proteins that activate heterotrimeric G-protein signaling in a receptor-independent manner were also identified using a functional screen in yeast (Cismowski et al., 1999). One of these proteins, denominated AGS1 (for activator of G-protein signaling 1), functions as a GEF for $\mathrm{G} \alpha_{\mathrm{i}} / \mathrm{G} \alpha_{\mathrm{o}}$ (Cismowski et al., 2000). Another protein, Pcp2 (Purkinje cell protein-2), expressed in Purkinje cells and retinal bipolar neurons was shown to function as a GEF for $\mathrm{G} \alpha_{\mathrm{o}}$ (Luo and Denker, 1999). It is still not clear whether these proteins work together with activated GPCRs to enhance or prolong signaling or if they function in the absence of a cell surface receptor.

It has been shown that Ric-8A functions as a GEF only for monomeric $\mathrm{G} \alpha$ subunits, which differs from the mechanism used by conventional GPCRs (Tall et al., 2003). If this is also the case for Ric-8B, it would mean that activation of G-protein by this putative GEF would depend on GPCR activation. That is, GPCR binding would lead to dissociation of $\mathrm{G} \alpha$ and $\mathrm{G} \beta \gamma$ subunits, and Ric- $8 \mathrm{~B}$ would then bind to $\mathrm{G} \alpha$ and promote the exchange of GDP for GTP before it reassociates with G $\beta \gamma$. This would ultimately lead to the amplification of the signal generated through receptor activation. Alternatively, it could be that monomeric $\mathrm{G} \alpha$ subunits residing on internal cellular membranes are the targets for the Ric-8 proteins (Pimplikar and Simons, 1993; Denker et al., 1996).

In our results with HEK293 cells, we could only detect increased G $\alpha$ olf activity by Ric- $8 \mathrm{~B}$ in the presence of an activated GPCR. This result is in agreement with the fact that Ric-8A cannot activate heterotrimeric G-proteins and indicates that the function of the Ric- 8 proteins depends on receptor activation. A protein member of the synembryn family (denominated hSyn) was also identified in humans (Klattenhoff et al., 2003). This protein, which is able to interact with $\mathrm{G} \alpha_{\mathrm{s}}$ and $\mathrm{G} \alpha$, is translocated to the plasma membrane in neuronal-derived cultured cells in response to isoproterenol or carbachol, indicating that its activity is also dependent on receptor activation (Klattenhoff et al., 2003).

\section{A putative GEF for Goolf}

It is known that the efficiency of signal transduction by GPCRs varies among different tissues. The $\alpha 2$ adrenergic receptors, for example, differ in their coupling to adenylyl cyclase when expressed over a range of receptor or G-protein concentrations in the two different cell types NIH-3T3 and PC12 (Sato et al., 1995). This is probably caused by the presence of different types of accessory proteins that might influence or enhance ligand-induced 
signaling. Although $\mathrm{G} \alpha$ olf is almost identical to $\mathrm{G} \alpha_{\mathrm{s}}$ in the amino acid sequence, it has been known for a long time that G $\alpha$ olf works poorly in heterologous systems when compared with $\mathrm{G} \alpha_{\mathrm{s}}$ (Jones and Reed, 1989; Jones et al., 1990). We show here that addition of Ric-8B to such a system can significantly improve the function of G $\alpha$ olf. This indicates that, indeed, accessory factors present in the olfactory neurons can play important roles in the efficiency of receptor coupling to G $\alpha$ olf. $\beta_{2} \mathrm{AR}$ has motifs that are conserved among ORs, and it has been demonstrated recently that the mouse $\beta_{2} \mathrm{AR}$ can substitute for an OR in glomerular formation when expressed from an OR locus (Feinstein et al., 2004). These results indicate that there are functional similarities between $\beta_{2} \mathrm{AR}$ and ORs. It remains to be determined whether functional expression of ORs in heterologous systems, which is usually very inefficient (for review, see Mombaerts, 2004), can also be improved by coexpression with G $\alpha$ olf and Ric-8B.

The olfactory system has evolved to detect rapid chemical signal changes in the environment. Rapid activation and rapid inactivation of the CAMP signal are fundamental for the proper functioning of the system. To be able to follow a scent trail released by an escaping prey or to be able to detect all of the chemical information present in a transient wind blow carrying the scent of a predator, it would be greatly advantageous to have an amplification mechanism for the olfactory signaling. Nevertheless, additional experiments should be performed to determine the physiological role of Ric- $8 \mathrm{~B}$ in vivo. It will be interesting, for example, to determine how mice that are deficient for Ric-8B compare with wild-type mice in terms of olfactory responses.

\section{A role for Ric-8B in the brain}

Goolf is expressed at high levels in some regions in the brain. Some of these regions, such as the striatum, nucleus accumbens, and olfactory tubercle, show very little or no expression of $\mathrm{G} \alpha_{\mathrm{s}}$, suggesting that G $\alpha$ olf may also function as an essential signaling G-protein in more central brain regions. The regions that express G $\alpha$ olf are responsible for the initiation and patterning of important behaviors, such as the control of the locomotor activity, drug reward, and habit formation (Gerdeman et al., 2003). In addition, these regions have been implicated in a series of neuropsychiatric and motor disorders, such as Parkinson's and Huntington diseases and Tourette's syndrome (Graybiel, 2000; Gerdeman et al., 2003). It was demonstrated that G $\alpha$ olf knockout mice show altered locomotor activities in response to cocaine or other $D_{1}$ receptor agonists (Zhuang et al., 2000). Thus, G $\alpha$ olf present in the striatum probably plays a role in the signal transduction mediated by $\mathrm{D}_{1}$ receptors in this area. It was also demonstrated that adenosine A2a receptors in striatum couple to G $\alpha$ olf (Kull et al., 2000). Because we found that Ric- $8 \mathrm{~B}$ is specifically coexpressed with G $\alpha$ olf in these same regions, it is possible that this putative GEF plays an important role in controlling critical aspects of the striatum function.

\section{References}

Belluscio L, Gold GH, Nemes A, Axel R (1998) Mice deficient in G(olf) are anosmic. Neuron 20:69-81.

Berghard A, Buck LB, Liman ER (1996) Evidence for distinct signaling mechanisms in two mammalian olfactory sense organs. Proc Natl Acad Sci USA 93:2365-2369.

Boekhoff I, Breer H (1992) Termination of second messenger signaling in olfaction. Proc Natl Acad Sci USA 89:471-474.

Boekhoff I, Tareilus E, Strotmann J, Breer H (1990) Rapid activation of alternative second messenger pathways in olfactory cilia from rats by different odorants. EMBO J 9:2453-2458.

Borisy F, Ronnet G, Cunningham A, Juilfs D, Beavo J, Snyder S (1992)
Calcium/calmodulin-activated phosphodiasterase expressed in olfactory receptor neurons. J Neurosci 12:915-923.

Breer H, Boekhoff I, Tareilus E (1990) Rapid kinetics of second messenger formation in olfactory transduction. Nature 345:65-68.

Brunet LJ, Gold GH, Ngai J (1996) General anosmia caused by a targeted disruption of the mouse olfactory cyclic nucleotide-gated cation channel. Neuron 17:681-693.

Buck L, Axel R (1991) A novel multigene family may encode odorant receptors: a molecular basis for odor recognition. Cell 65:175-187.

Buck LB (2000) The molecular architecture of odor and pheromone sensing in mammals. Cell 100:611-618.

Chen TY, Yau KW (1994) Direct modulation by $\mathrm{Ca}^{2+}$-calmodulin of cyclic nucleotide-activated channel of rat olfactory receptor neurons. Nature 368:545-548.

Cismowski MJ, Takesono A, Ma C, Lizano JS, Xie X, Fuernkranz H, Lanier SM, Duzic E (1999) Genetic screens in yeast to identify mammalian nonreceptor modulators of G-protein signaling. Nat Biotechnol $17: 878-883$.

Cismowski MJ, Ma C, Ribas C, Xie X, Spruyt M, Lizano JS, Lanier SM, Duzic E (2000) Activation of heterotrimeric G-protein signaling by a Rasrelated protein. J Biol Chem 275:23421-23424.

Conklin BR, Farfel Z, Lustig KD, Julius D, Bourne HR (1993) Substitution of three amino acids switches receptor specificity of $\mathrm{Gq} \alpha$ to that of $\mathrm{Gi} \alpha$. Nature 363:274-276.

Denker SP, Mc Caffery JM, Palade GE, Insel PA, Farquhar MG (1996) Differential distribution of alpha subunits and beta gamma subunits of heterotrimeric proteins in Golgi membranes of the exocrine pancreas. J Cell Biol 133:1027-1040.

Feinstein P, Bozza T, Rodriguez I, Vassalli A, Mombaerts P (2004) Axon guidance of mouse olfactory sensory neurons by odorant receptors and the $\beta 2$ adrenergic receptor. Cell 117:833-846.

Finley RL, Brent R (1994) Interaction mating reveals binary and ternary connections between Drosophila cell cycle regulators. Proc Natl Acad Sci USA 91:12980-12984.

Firestein S (2001) How the olfactory system makes scents of scents. Nature 413:211-218.

Gerdeman GL, Partridge JG, Lupica CR, Lovinger DM (2003) It could be habit forming: drugs of abuse and striatal synaptic plasticity. Trends Neurosci 26:184-192.

Golemis E, Serebriiskii I, Finley R, Kolonin M, Gyuris J, Brent R (1999) Interaction trap/two-hybrid system to identify interacting proteins. In: Current protocols in molecular biology, pp 20.1.1-20.1.40. New York: Wiley.

Graybiel AM (2000) The basal ganglia. Curr Biol 10:R509-R511.

Hall A (1998) G proteins and small GTPases: distant relatives keep in touch. Science 280:2074-2075.

Hervé D, Lévi-Strauss M, Marey-Semper I, Verney C, Tassin J-P, Glowinski J, Girault JA (1993) $\mathrm{G}_{\text {olf }}$ and $\mathrm{G}_{\mathrm{s}}$ in rat basal ganglia: possible involvement of $G_{\text {olf }}$ in the coupling of dopamine $D_{1}$ receptor with adenylyl cyclase. J Neurosci 13:2237-2248.

Hervé D, Le Moine C, Corvol JC, Belluscio L, Ledent C, Fienberg AA, Jaber M,

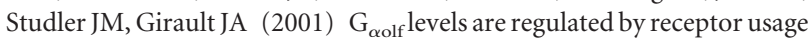
and control dopamine and adenosine action in the striatum. J Neurosci 21:4390-4399.

Jones DT, Reed RR (1989) Golf: an olfactory neuron-specific G-protein involved in odorant signal transduction. Science 244:790-795.

Jones DT, Masters SB, Bourne HR, Reed RR (1990) Biochemical characterization of three stimulatory GTP-binding proteins. J Biol Chem 265:2671-2676.

Klattenhoff C, Montecino M, Soto X, Guzmán L, Romo X, García MLA, Mellstrom B, Naranjo JR, Hinrichs MV, Olate J (2003) Human brain synembryn interacts with Gs $\alpha$ and Gq $\alpha$ and is translocated to the plasma membrane in response to isoproterenol and carbachol. J Cell Physiol 195:151-157.

Kull B, Svenningsson P, Fredholm BB (2000) Adenosine $\mathrm{A} 2_{\mathrm{A}}$ receptors are colocalized with and activate $\mathrm{G}_{\mathrm{olf}}$ in rat striatum. Mol Pharmacol 58:771-777.

Kurahashi T, Menini A (1997) Mechanism of odorant adaptation in the olfactory receptor cell. Nature 385:725-729.

Liu H-Y, Wenzel-Seifert K, Seifert R (2001) The olfactory G-protein $G_{\alpha o l f}$ possesses a lower GDP-affinity and deactivates more rapidly than 
$\mathrm{G}_{\mathrm{s} \alpha}$ short: consequences for receptor-coupling and adenylyl cyclase activation. J Neurochem 78:325-338.

Luo Y, Denker BM (1999) Interaction of heterotrimeric $\mathrm{G}$ protein $\mathrm{G} \alpha$ o with Purkinje Cell Protein-2. J Biol Chem 274:10685-10688.

Miller KG, Rand JB (2000) A role for RIC-8 (Synembrin) and GOA-1 (Go $\alpha$ ) in regulating a subset of centrosome movements during early embryogenesis in Caenorhabditis elegans. Genetics 156:1649-1660.

Miller KG, Alfonso A, Nguyen M, Crowell JA, Johnson CD, Rand JB (1996) A genetic selection for Caenorhabditis elegans synaptic transmission mutants. Proc Natl Acad Sci USA 93:12593-12598.

Miller KG, Emerson MD, McManus JR, Rand JB (2000) RIC-8 (Synembrin): a novel conserved protein that is required for $\mathrm{Gq} \alpha$ signaling in the C. elegans nervous system. Neuron 27:289-299.

Mombaerts P (2004) Genes and ligands for odorant, vomeronasal and taste receptors. Nat Rev Neurosci 5:263-278.

Munger SD, Lane AP, Zhong H, Leinders-Zufall T, Yau KW, Zufall F, Reed RR (2001) Central role of the CNG4 channel subunit in $\mathrm{Ca}^{2+}$ calmodulin-dependent odor adaptation. Science 294:2172-2175.

Peppel K, Boekhoff I, McDonald P, Breer H, Caron MG, Lefkowitz RJ (1997) G protein-coupled receptor kinase 3 (GRK3) gene disruption leads to loss of odorant receptor desensitization. J Biol Chem 272:25425-25428.

Pimplikar SW, Simons K (1993) Regulation of apical transport by a Gs class of heterotrimeric $G$ protein. Nature 362:456-458.

Ronnett GV, Moon C (2002) G proteins and olfactory signal transduction. Annu Rev Physiol 64:189-222.

Sato M, Kataoka R, Dingus J, Wilcox M, Hildebrandt JD, Lanier SM (1995) Factors determining specificity of signal transduction by G-proteincoupled receptors. J Biol Chem 270:15269-15276.

Sato M, Ribas C, Hildebrandt JD, Lanier SM (1996) Characterization of a G-protein activator in the neuroblastoma-glioma cell hybrid NG10815*. J Biol Chem 271:30052-30060.
Schaeren-Wiemers N, Gerfin-Moser A (1993) A single protocol to detect transcripts of various types and expression levels in neural tissue and culture cells: in situ hybridization using digoxigenin-labelled cRNA probes. Histochemistry 100:431-440.

Sinnarajah S, Dessauer CW, Srikumar D, Chen J, Yuen J, Yilma S, Dennis JC, Morrison EE, Vodyanoy V, Kehrl JH (2001) RGS2 regulates signal transduction in olfactory neurons by attenuating activation of adenylyl cyclase III. Nature 409:1051-1055.

Sprang S (2001) GEFs: master regulators of G-protein activation. Trends Biochem Sci 26:266-267.

Strittmatter SM, Valenzuela D, Kennedy TE, Neer E, Fishman MC (1990) $\mathrm{G}_{\mathrm{o}}$ is a major growth cone protein subject to regulation by GAP-43. Nature 344:836-841.

Tall GG, Krumins AM, Gilman AG (2003) Mammalian Ric-8A (synembryn) is a heterotrimeric $\mathrm{G} \alpha$ protein guanine nucleotide exchange factor J Biol Chem 278:8356-8362.

Wei J, Zhao AZ, Chan GCK, Baker LP, Impey S, Beavo JA, Storm DR (1998) Phosphorylation and inhibition of olfactory adenylyl cyclase by CaM kinase II in neurons: a mechanism for attenuation of olfactory signals. Neuron 21:495-504.

Wong ST, Trinh K, Hacker B, Chan GCK, Lowe G, Gaggar A, Xia Z, Gold GH, Storm DR (2000) Disruption of the type III adenylyl cyclase gene leads to peripheral and behavioral anosmia in transgenic mice. Neuron 27:487-497.

Zheng C, Feinstein P, Bozza T, Rodriguez I, Mombaerts P (2000) Peripheral olfactory projections are differentially affected in mice deficient in a cyclic nucleotide-gated channel subunit. Neuron 26:81-91.

Zhuang X, Belluscio L, Hen R (2000) $\mathrm{G}_{\text {olf } \alpha}$ mediates dopamine $\mathrm{D}_{1}$ receptor signaling. J Neurosci 20:RC91(1-5).

Zufall F, Leinders-Zufall T (2000) The cellular and molecular basis of odor adaptation. Chem Senses 25:473-481. 